\title{
3.05
}

\section{Demandas judiciais e assistência farmacêutica: princípios constitucionais e políticas públicas ${ }^{1}$}

Legal claim and pharmaceutical assistance: constitutional principles and public policy

\section{Arlandia Cristina Lima Nobre}

Farmacêutica, Bacharel em Direito, Doutora em Farmacologia, Profa. Adjunta do Curso de Farmácia da Universidade de Fortaleza, Brasil.

\section{Juliana Leite de Barros Lima}

Farmacêutica. Bacharel em Farmácia. Universidade de Fortaleza, Brasil

\section{Mayara Mendonça Bastos}

Farmacêutica. Bacharel em Farmácia. Universidade de Fortaleza, Brasil

\author{
Nívia Tavares Pessoa \\ Farmacêutica, Mestre em Ciências Farmacêuticas, Especialista em Gestão da \\ Assistência Farmacêutica. Fortaleza, Brasil
}

\section{José Filomeno de Moraes Filho}

Advogado, Doutor em Direito, Procurador do Estado do Ceará, Prof. Titular do Programa de Pós-Graduação em Direito Constitucional da Universidade de Fortaleza. Brasil

Resumo: Apesar das políticas públicas realizadas pelo Sistema Único de Saúde (SUS), muitos indivíduos ingressam com ação judicial, intensificando o fenômeno da judicialização da saúde. A pesquisa teve como objetivo analisar as demandas judiciais na assistência farmacêutica do estado do Ceará diante das políticas públicas e dos princípios constitucionais. Trata-se de um estudo documental, transversal, retrospectivo, quantitativo e descritivo. Foi analisado o perfil sócio-demográfico do autor da ação judicial; as características processuais, médico-sanitárias e políticoadministrativas; impacto das demandas extra-orçamentárias nas contas públicas e atendimento dos preceitos constitucionais. Foram analisadas 347 ações (192 coletivas e 155 individuais). Os resultados apontam para o maior índice de mulheres, na faixa etária

\footnotetext{
${ }^{1}$ Trabalho apresentado no Curso de Direito da Universidade de Fortaleza, na forma de monografia, no dia 29 de novembro de 2011.
} 
de 51-70 anos, domiciliadas em Fortaleza. O processo encontra-se em andamento, sendo conduzido pelo advogado privado e defensoria pública, nas individuais e, pelo Ministério Público, nas coletivas. Dentre as doenças destacam-se as neoplasias, tratadas com transtuzumabe e rituximabe, prescritos sob nome de marca em número significativo, impedindo a intercambialidade. Apesar de estarem registrados na ANVISA, nem todos estão contemplados nos protocolos clínicos e diretrizes terapêuticas. Ao conceder a antecipação da tutela têm-se desde o início assegurado o princípio da universalidade e integralidade, entretanto, não restou comprovado à aplicação da equidade. É inegável o aumento dos gastos públicos, particularmente por ser de origem extra-orçamentária. Em síntese, é necessária uma comissão de "peritos" em conjunto com o judiciário nas decisões relacionadas às demandas de acesso a medicamentos viabilizando a gestão da assistência farmacêutica e do SUS, de modo a garantir o uso racional.

Palavras-chave: Assistência farmacêutica; direito à saúde; equidade em saúde; judicialização.

Keywords: Pharmaceutical assistance; right to health; health equity; judicialization

\section{Introdução}

Amparado por um conceito amplo de saúde, o SUS foi criado pela Constituição Federal de 1988, para ser o sistema de saúde dos mais de 180 milhões de brasileiros (Brasil, 2000), com o propósito de abranger todas as necessidades do ser humano relacionados à saúde, devendo suas ações e serviços ser prestados de maneira completa, sem exclusões de doenças ou patologias, quer por dificuldades técnicas, quer por questões financeiras do poder público. "Não é permitido a este esquivar-se da prestação de saúde em todos os setores” (Tavares, 2008, p. 787).

Em decorrência das amplas necessidades e da limitação dos recursos disponíveis na área da saúde, muitas vezes, faz-se necessário à seleção de prioridades. Dessa forma, as decisões de priorização de recursos públicos nos cuidados de saúde, buscam proporcionar maior atendimento as situações que envolvem um maior número de pessoas, em especial, as mais vulneráveis. Para tanto, o Ministério da Saúde tem formulado e publicado protocolos clínicos e diretrizes terapêuticas para as diversas doenças, tendo como objetivo a criação de mecanismos para a garantia da prescrição segura e eficaz, através da padronização dos medicamentos (Brasil, 2004).

Considerando que nas ações de saúde, na maioria das vezes, são utilizados os medicamentos, como componente estratégico, cujo objetivo pode ser terapêutico, profilático e de diagnóstico, é facilmente perceptível que a assistência farmacêutica 
representa hoje um setor de grande impacto financeiro no âmbito do Ministério da Saúde e das Secretarias Estaduais e Municipais de Saúde, em virtude da crescente procura por estes insumos. A gestão precisa fazer um planejamento estratégico, bem como um gerenciamento efetivo para garantir o seu acesso e, com isso assegurar o direito a saúde que é um preceito constitucional.

Todavia frequentemente é possível perceber a falta do medicamento. De acordo com Martins; Mendes e Nascimento (2010, p. 356) "tratando-se de um direito fundamental, é de se indagar se não cabe ao judiciário determinar que se cumpram os desígnios constitucionais, visando a suprir essa omissão estatal". Entretanto, segundo os mesmos autores (p.356) "há, ainda, aqueles que vêem com restrição os aportes financeiros para a consecução desse desiderato, sob a alegação de que isso constitui desvio de finalidade do planejamento governamental. Em assim sendo, o suprimento dessas áreas necessitadas comprometeria de forma danosa o orçamento público em detrimento dos programas aprovados".

Diante desta situação fática, o usuário mais esclarecido e necessitado de ver atendida a sua necessidade, procura o poder judiciário para ter seu pedido analisado e dessa forma, garantir a assistência à saúde, através do fornecimento de medicamentos, outros insumos e procedimentos médicos; fenômeno denominado “judicialização da saúde". Não se trata apenas de um interesse financeiro do Estado, que tem seu planejamento, programação e alocação de recursos questionados, mas da transferência do foco do coletivo para a esfera individual, quando se analisa apenas o caso concreto.

É fato que esta judicialização tem acarretado um forte impacto financeiro e orçamentário no SUS em decorrência do crescente número de ações judiciais envolvendo a Assistência Farmacêutica. Há um comprometimento de todo um planejamento, afetando o plano de ação que antecede a prática das políticas públicas de saúde (Naffah Filho et al., 2010). Por outro lado, deve-se ponderar que por trás destas demandas existe o sofrimento humano, a necessidade, muitas vezes urgente, pela prestação do serviço de saúde.

Vale ressaltar que o SUS garante o acesso ao tratamento seja qual for o tipo e a complexidade do problema apresentado. O que se apresenta nas demandas judiciais frequentemente são ações buscando o acesso a produtos não previstos nos protocolos terapêuticos e programas executados pelo SUS, em razão de preços 
abusivos praticados pelos fabricantes ou de falta de estoque, padronização do uso, registro no país e comprovação científica de eficácia.

É importante avaliar se o acolhimento das demandas judiciais, não representa a concessão de certo privilégio para aqueles indivíduos com poder aquisitivo para contratar um advogado e acionar o Estado. É necessário determinar se, de fato, os princípios da universalidade, integralidade e equidade (igualdade material) estão sendo considerados verdadeiramente; afinal a decisão judicial afeta única e exclusivamente a(s) parte(s) autora(s) da referida ação.

Por outro lado, se os recursos estão sendo destinados ao cumprimento das decisões judiciais, que em regra não estão previstos no orçamento, é possível que a execução das ações de saúde sejam afetadas e com elas, todos aqueles que "dependem" exclusivamente do SUS (Chieffi; Barata, 2009). A atribuição de encargos ao Executivo sem considerar os recursos disponíveis e os programas e ações que o governo realiza, pode caracterizar lesão ao princípio constitucional da independência e harmonia dos poderes, além de impossibilitar a implementação das políticas públicas e por que não dizer, do próprio Sistema de Saúde.

Dessa forma, alguns entendem que a prestação de serviços públicos pelo Estado está condicionada a disponibilidade dos respectivos recursos dentro de uma "reserva do possível" (Bigolin, 2004; Scaff, 2006), cabendo ao poder executivo determinar as prioridades a serem atendidas.

Em razão disso, o presente estudo teve como objetivo analisar as demandas judiciais na assistência farmacêutica do Estado do Ceará, traçando o perfil sócio-demográfico do autor da ação judicial; determinando as características processuais e médico-sanitárias; avaliando as características político-administrativas, e o atendimento dos preceitos constitucionais.

\section{Metodologia}

Trata-se de um estudo documental, transversal, retrospectivo, quantitativo e descritivo. Realizado a partir dos processos judiciais, disponíveis no arquivo documental do COASF/SESA (Coordenadoria de Assistência Farmacêutica da Secretaria de Saúde do Estado do Ceará) relativos ao período de 01 de janeiro a 31 de dezembro de 2010. O COASF é o órgão responsável pela execução da política de medicamentos do Ceará e está vinculado à Secretaria de Saúde do Estado.

A coleta de dados foi realizada nos meses de maio a setembro de 2011, através do 
preenchimento de um formulário próprio contendo variáveis que foram selecionadas do Manual de indicadores de avaliação e monitoramento das demandas judiciais de medicamentos elaborado pela Escola Nacional de Saúde Pública / Fiocruz (Pepe, 2011).

a) Características sócio-demográficas do autor da ação judicial

- População por sexo e faixa etária;

- População por município, regional e bairro de domicílio do autor (Extratos de vulnerabilidade social).

b) Características processuais das ações judiciais

- Ações judiciais por representação do autor da ação (Defensoria Pública, Ministério Público e representação jurídica privada);

- Status da ação (julgada ou em andamento).

c) Características médico-sanitárias das ações judiciais

- Medicamentos por subgrupo terapêuticos/ farmacológicos/ substância química;

- Medicamentos prescritos pelo nome genérico;

- Diagnósticos principais, por categoria diagnóstica.

d) Características político administrativas das ações judiciais

- Medicamentos registrados na Agência Nacional de Vigilância Sanitária

A análise dos dados foi realizada calculando-se a frequência simples de todas as variáveis e porcentagem, com o intuito de descrever as principais características dos processos, utilizando o programa Epi-info versão 3.5.3.

A pesquisa foi aprovada pelo Comitê de Ética em Pesquisa da Universidade de Fortaleza sob o no 362/2011 em conformidade com a resolução no 196/96 do Conselho Nacional de Saúde, sendo assegurado à privacidade e o sigilo das informações, preservando o anonimato dos pacientes, médico prescritor e condutor da ação. A coleta de dados ocorreu mediante assinatura do termo de fiel depositário pelo responsável da COASF, autorizando o pleno acesso do pesquisador aos dados dos mandados judiciais contra o Estado do Ceará.

\section{Resultados e discussão}

No período de estudo foram analisados 347 processos judiciais contra a Secretaria Estadual de Saúde do Ceará. Observa-se que a inserção do Poder Judiciário no campo da saúde está cada vez mais concreta. Trata-se do poder de agir 
do cidadão, direito subjetivo, fundado em norma de direito público.

A maioria dos processos $(234 ; 67,4 \%)$ foi impetrada pelo sexo feminino (Tabela 1). Pessoa (2007) demonstrou que a maioria das ações também foi impetrada por mulheres, com valores bastante semelhantes (64,2\%) ao encontrado neste estudo, considerando as solicitações administrativas e judiciais avaliadas no período de janeiro de 2004 a junho de 2006 no estado do Ceará. As mulheres foram as principais solicitantes provavelmente em função da maior preocupação e procura pelos serviços de saúde (Machado et. al., 2011; Pessoa, 2007); ou pela elevada incidência de câncer de mama, dentre as patologias que motivaram as demandas judiciais.

As principais faixas etárias (Tabela 1) foram entre 41 a $50(20,5 \%), 51$ a 60 anos $(20,7 \%)$ e 61 a 70 anos (17,0\%). Ressalta-se que nesta última faixa existe a prerrogativa do benefício diferencial por tratar-se de pessoas idosas em conformidade com o art. $15, \S 2^{\circ}$ do Estatuto do Idoso. Não foram avaliadas as possíveis inadequações de prescrição por grupos etários específicos. Em estudo realizado por Vieira e Zucchi (2007) as faixas mais envolvidas foram de zero a 19 anos (30,7\%) e de 70 a 79 anos (23,9\%); enquanto por Pessoa (2007) destacam-se as de 30 a 39 anos e de 40 a 49 anos. Havendo divergência com os resultados ora apresentados, exceto quanto ao último.

Tabela 1 - Autores dos processos judiciais impetrados contra a Secretaria Estadual de Saúde do Ceará, segundo o sexo e faixa etária. Janeiro a dezembro de 2010

\begin{tabular}{lccc}
\hline \multicolumn{1}{c}{ Sexo } & $\mathrm{f}$ & $\%$ & $\mathrm{IC}(\%)$ \\
\hline Feminino & 234 & 67,4 & $62,2-72,3$ \\
Masculino & 113 & 32,6 & $27,7-37,8$ \\
\hline Total & 347 & 100,0 & -
\end{tabular}

\begin{tabular}{lccc}
\hline $\begin{array}{c}\text { Faixa Etária } \\
\text { (anos) }\end{array}$ & & & \\
\hline $01-10$ & 15 & 4,3 & $2,5-7,2$ \\
$11-20$ & 25 & 7,2 & $4,8-10,6$ \\
$21-30$ & 25 & 7,2 & $4,8-10,6$ \\
$31-40$ & 34 & 9,8 & $7,0-13,5$ \\
$41-50$ & 71 & 20,5 & $16,4-25,2$ \\
$51-60$ & 72 & 20,7 & $16,7-25,5$ \\
$61-70$ & 59 & 17,0 & $13,3-21,5$ \\
$71-80$ & 36 & 10,4 & $7,5-14,2$ \\
$81-90$ & 10 & 2,9 & $1,5-5,4$ \\
\hline Total & 347 & 100,0 & - \\
\hline
\end{tabular}

Fonte: COASF; f: freqüência; IC: Intervalo de Confiança 
A ocupação (profissão) da parte autora, indicada na qualificação, estava presente em 174 processos judiciais. Destaca-se a categoria de aposentados $(n=81)$, estudante $(n=30)$, dona do lar $(n=23)$ e agricultor $(n=10)$ com 46,6, 17,2, 13,2 e 5,7\% dos processos, respectivamente. As demais categorias relatadas incluíam doméstica $(n=9)$, comerciante $(n=7)$, desempregado $(n=7)$, professor $(n=4)$, motorista $(m=2)$ e técnico $(n=1)$, perfazendo um total de $17,3 \%$ do total. Neste sentido é provável supor a vulnerabilidade financeira das partes litigantes.

Com relação ao domicílio do solicitante da ação judicial, considerou-se o lugar onde ele estabelece sua residência com âmbito definitivo (art. 70 do código civil/2002), declarado no processo (Tabela 2). Tendo em vista que a informação é dada pelo solicitante da ação, pode ocorrer um comprometimento da mesma, se considerar que o atendimento seja preferencial para a população adstrita a um determinado serviço de saúde.

Tabela 2 - Processos judiciais segundo o município de domicílio do autor. Ceará, janeiro a dezembro de 2010.

\begin{tabular}{cccc}
\hline Município & $\mathbf{f}$ & $\%$ & $\%$ acumulado \\
\hline Região Metropolitana & 243 & 70,0 & 70,0 \\
Fortaleza & - & - & 70,0 \\
Aquiraz & 9 & 2,6 & 72,6 \\
Caucaia & 1 & 0,3 & 72,9 \\
Cascavel & - & - & 72,9 \\
Chorozinho & 2 & 0,6 & 73,5 \\
Euzébio & 1 & 0,3 & 73,8 \\
Guaiúba & 2 & 0,6 & 74,4 \\
Horizonte & - & - & 74,4 \\
Itaitinga & 12 & 3,4 & 77,8 \\
Maracanaú & 4 & 1,2 & 79,0 \\
Maranguape & 1 & 0,3 & 79,3 \\
Pacajus & - & - & 79,3 \\
Pacatuba & - & - & 79,3 \\
Pindoretama & - & - & 79,3 \\
São Gonçalo & 72 & 20,7 & 100,0 \\
Interior & 347 & 100,0 & - \\
\hline Total & & &
\end{tabular}

Fonte: COASF; f: Frequência 
A busca pela materialização dos direitos constitucionais está se apresentando com a luta no campo do Direito através de duas frentes distintas: uma individual e outra coletiva. A tabela 3 demonstra que $192(55,3 \%)$ ações foram coletivas, sendo impetradas quase que na totalidade pelo Ministério Público (99,5\%); existe uma (01) única ação pela Defensoria, ambas as partes legítimas para propor ação civil pública principal e cautelar. Considerou-se o total de autores das ações coletivas, que estavam contemplados em 49 processos judiciais.

De acordo com a CF/88, em seu art. 129, II, cabe ao Ministério Público zelar pelo efetivo cumprimento dos serviços de relevância pública, promovendo as medidas necessárias a sua garantia. Destaca-se que, os serviços de saúde são considerados de relevância pública (art. 197 CF/88). "Dessa forma, o Ministério Público poderá, em defesa do direito fundamental à saúde, fiscalizar e praticar as iniciativas necessárias e pertinentes para zelar pela efetiva prestação e qualidade de todas as ações e serviços relacionados à saúde pública" (Moraes, 2006, p.2098).

Nas Ações individuais $(n=155)$, o principal condutor foram os advogados particulares $(47,7 \%)$, seguido da Defensoria Pública $(43,2 \%)$, enquanto a instituição judicial, Ministério Público, respondeu por $9 \%$.

Tabela 3 - Processos judiciais segundo o tipo da ação e o condutor. Ceará, janeiro a dezembro de 2010.

\begin{tabular}{l|ccccc}
\hline \multirow{2}{*}{ Tipo de ação } & \multicolumn{5}{|c}{ Condutor da ação f (\%) } \\
\cline { 2 - 6 } & Defensoria & MP & Particular & Total & $\chi^{2}$ \\
\hline Coletiva & $1(0,5)$ & $191(99,5)$ & - & 192 & 0,0000 \\
Individual & $67(43,2)$ & $14(9)$ & $74(47,7)$ & 155 & 0,0000 \\
\hline Total & $68(19,6)$ & $205(59,1)$ & $74(21,3)$ & 347 & - \\
\hline
\end{tabular}

Fonte: COASF

f: Freqüência; MP: Ministério Público; Particular: advocacia privada; $\chi 2:$ Qui-quadrado

É preciso ponderar que um dos principais obstáculos ao acesso efetivo à justiça está na disponibilidade financeira para pagar as custar processuais e suportar as delongas de um processo. Conforme dispõe Vale (2009, p. 16):

A resolução judicial dos litígios é muito dispendiosa na maior parte das sociedades modernas. Enquanto o Estado se encarrega dos salários dos juízes e servidores, prédios e outros recursos necessários aos julgamentos, cabem aos litigantes suportar a grande proporção dos demais custos necessários à solução de uma lide, o que inclui os honorários advocatícios e algumas custas judiciais. As pessoas, 
naturais ou jurídicas, que possuem recursos financeiros consideráveis a serem utilizados gozam de vantagens ao propor ou defender ações judiciais.

O estudo demonstrou que um grande número de ações foi impetrada pela advocacia privada, o que poderia refletir o poder aquisitivo favorável da parte litigante. Todavia, em tais ações foram solicitados os benefícios da gratuidade judiciária atendendo ao disposto na Lei nำ1.060, de 5 de fevereiro de 1950 e Lei no 7.115 , de 29 de agosto de 1983.

Do total de ações impetradas pela advocacia privada, 39,2\% tiveram como condutor o mesmo advogado. Curiosamente, ao consultar o site do Tribunal de Justiça do Ceará, observou-se que durante o período de janeiro a dezembro de 2010 e janeiro a outubro de 2011, este profissional foi responsável por 155 ações, sendo que todas apresentam como causa de pedir, tratamento médico-hospitalar e/ou fornecimento de medicamentos, impetradas contra a fazenda pública. Parece que surge um mercado que favorece a especialização nesse tipo de ação. Neste caso, o Estado é sempre o requerido.

A Defensoria Pública, instituição essencial à função jurisdicional do Estado, também foi responsável pela condução de um número significativo de ações, fazendo crer que a parte autora era necessitada, na forma do art. $5^{\circ}$, LXXIV da CF/88. Vale ressaltar que, não foi possível inferir a real condição socioeconômica do solicitante, cabendo ao juiz decidir pela concessão ou não da gratuidade judiciária.

Nos processos analisados que visavam o acesso à saúde pelo Poder Judiciário, sempre existia o pedido de liminar que era deferido sem a ouvida da parte contrária. Dessa forma, o Estado arca imediatamente com o pagamento do bem requerido, sem que haja um processo de licitação, causando na visão de Machado (2008), um prejuízo ao orçamento destinado à saúde. Somente em um processo não foi concedida a tutela antecipada.

A liminar ou antecipação da tutela, prevista no art. 273 do CPC, tem sido instrumento para garantir a efetividade do direito das partes, antes do julgamento do mérito da ação, desde que seja apresentada a prova inequívoca e o perigo na mora e, que o juiz se convença da verossimilhança.

Quanto às características processuais das ações judiciais referentes ao status, foram analisadas somente as ações individuais. Para tanto, foi realizado uma consulta no site do Tribunal de Justiça do Ceará no período de outubro de 2011, nos 
processos que se encontravam digitalizados e que, portanto, puderam ser acessados online. Os resultados refletem uma amostra equivalente a 64,5\% ( $n=100)$ das demandas individuais e demonstram que a grande maioria (89\%) encontra-se em andamento (Tabela 4), confirmando que o processo judicial requer muito tempo para ser concluído.

Tabela 4 - Ações judiciais segundo o status, Ceará, janeiro a dezembro de 2010

\begin{tabular}{l|rc}
\hline Status da ação (individual) & $\mathbf{f}$ & $\%$ \\
\hline Andamento & 89 & 89,0 \\
Julgado & 2 & 2,0 \\
Julgamento antecipado da lide & 4 & 4,0 \\
Arquivado & 2 & 2,0 \\
Extinto & 3 & 3,0 \\
\hline Total & 100 & 100,0 \\
\hline
\end{tabular}

Fonte: COASF

Andamento: ação que tramita regularmente; Julgado: decisão judicial final proferida a conclusão do processo em primeira instância; Julgamento antecipado da lide: sentença proferida por tratar de questão unicamente de direito e/ou não houver necessidade de produzir provas; Arquivado: pedido de desistência e/ou falta de interesse da parte; Extinto: ação transitado em julgado sem análise de mérito em função do falecimento da parte autora.

As doenças mais frequentes, de acordo com a $10^{\underline{a}}$ Classificação Estatística Internacional de Doenças e Problemas Relacionados com a Saúde, da Organização Mundial da Saúde (CID-10), estão dispostas na Tabela 5.

Nos 347 processos analisados constavam descritas 357 doenças, das quais, as neoplasias responderam por 229, sendo o câncer de mama responsável por 99 destes. Vale ressaltar que, existiam processos onde o autor da ação apresentava mais de uma co-morbidade, isto explica o total de doença $(n=357)$ ultrapassar o total de processos.

Observa-se nos últimos tempos uma modificação nos padrões saúde-doença no mundo, através da mudança no perfil de mortalidade, com diminuição das taxas de doenças infecciosas e aumento concomitante da taxa de doenças crônicodegenerativas, entre elas, as neoplasias (Andrade et al., 2008). Ao mesmo tempo, é possível justificar as elevadas demandas decorrentes das neoplasias, por ser essa, uma enfermidade cujo tratamento terapêutico apresenta um custo extremamente alto, 
sendo custeado na maioria dos casos pelo SUS. Tais medicamentos sequer são comercializados no comércio varejista farmacêutico.

Tabela 5 - Doenças, por grupo, de acordo com a classificação CID-10 dos demandantes de processos judiciais. Ceará, janeiro a dezembro de 2010

\begin{tabular}{|c|c|c|c|}
\hline & Doenças & f & $\%$ \\
\hline C00-D48 & Neoplasias & 229 & 64,15 \\
\hline $100-199$ & Doenças do aparelho circulatório & 30 & 8,40 \\
\hline E00-E90 & Doenças endócrinas, nutricionais e metabólicas & 25 & 7,00 \\
\hline M00-M99 & Doenças do sistema osteomuscular e do tecido & 19 & 5,32 \\
\hline G00-G99 & Doenças do sistema nervoso & 17 & 4,76 \\
\hline F00-F99 & Transtornos mentais e comportamentais & 11 & 3,08 \\
\hline $\mathrm{H} 00-\mathrm{H} 59$ & Doenças do olho e anexos & 6 & 1,68 \\
\hline D50-D89 & $\begin{array}{l}\text { Doenças do Sangue e dos órgãos } \\
\text { hematopoiéticos e alauns }\end{array}$ & 5 & 1,40 \\
\hline A00-B99 & Algumas doenças infecciosas e parasitárias & 5 & 1,40 \\
\hline L00-L99 & Doenças da pele e do tecido subcutâneo & 3 & 0,85 \\
\hline J00-J99 & Doenças do aparelho respiratório & 2 & 0,56 \\
\hline N00-N99 & Doenças do aparelho geniturinário & 2 & 0,56 \\
\hline K00-K93 & Doenças do aparelho digestivo & 1 & 0,28 \\
\hline S00-T98 & Lesões, envenenamento e algumas outras & 1 & 0,28 \\
\hline \multirow[t]{2}{*}{ Z00-Z99 } & $\begin{array}{l}\text { Fatores que influenciam o estado de saúde } \\
\text { e o contato com servicos de saúde }\end{array}$ & 1 & 0,28 \\
\hline & Total & 357 & 100,00 \\
\hline
\end{tabular}

Fonte: COASF; F: freqüência; CID: classificação internacional de doenças

De acordo com a classe terapêutica (1ํㅡível da classificação ATC) constatouse que os medicamentos de maior prevalência $(n=238)$ estavam disposto no grupo L- antineoplásicos e agentes imunomoduladores, cuja principal indicação é para o tratamento de neoplasias (Tabela 6). 
Tabela 6 - Medicamentos pleiteados, segundo o $1^{\circ}$ nível do ATC, Secretaria Estadual de Saúde, Ceará, janeiro a dezembro de 2010

\begin{tabular}{l|cc}
\hline Código ATC & f & $\%$ \\
\hline L - Antineoplásicos e agentes imunomoduladores & 238 & 66,1 \\
N - Sistema nervoso & 35 & 9,7 \\
A - Aparelho digestivo e metabólico & 19 & 5,3 \\
H - Hormônios de uso sistêmico excluídos os sexuais & 17 & 4,7 \\
R - Aparelho respiratório & 14 & 3,9 \\
B - Sangue e órgãos hematopoiéticos & 14 & 3,9 \\
C - Aparelho cardiovascular & 9 & 2,5 \\
J - Antiinfecciosos sistêmicos & 6 & 1,7 \\
M - Aparelho músculo esquelético & 4 & 1,1 \\
D - Dermatologia & 3 & 0,8 \\
V - Vários & 1 & 0,3 \\
\hline Total & 360 & 100 \\
\hline
\end{tabular}

ATC (Anatomical Therapeutic Chemical): sistema de classificação dos medicamentos.

Dentre os medicamentos L-antineoplásicos e agentes imunomoduladores mais solicitados destacam-se: Transtuzumabe $(n=90)$ em $25 \%$ das solicitações e, Rituximabe ( $n=57)$, representando $15,8 \%$ do total. Seguramente, estes medicamentos foram responsáveis pela grande maioria das demandas, perfazendo $40,8 \%$ do total que incluíam 60 tipos diferentes de medicamentos.

O Transtuzumabe é considerado uma terapia-alvo, sendo aplicado com relativo sucesso no câncer de mama. Somente no ano de 2009, segundo dados da COASF, os gastos com esse medicamento pela SESA-CE chegaram a $\mathrm{R} \$ 1.082 .985,88$ (Hum milhão oitenta e dois mil novecentos e oitenta e cinco reais e oitenta e oito centavos) (Haddad, 2011). A elevada solicitação de Transtuzumabe nos processos avaliados pode ser explicada pelo número de portadores de câncer de mama.

De acordo com a nota técnica 2010 do Ministério da Saúde, seu fornecimento, para uso oncológico, dar-se-á por meio de procedimentos quimioterápicos no subsistema APAC (Autorização de procedimento de alta complexidade), do Sistema de Informações Ambulatoriais do SUS; isto quer dizer que, pode ser solicitado por demanda administrativa, devendo ser fornecido por estabelecimentos credenciados e habilitados em Oncologia; sendo posteriormente ressarcidos pela respectiva Secretária de Saúde gestora, que repassa o recurso para tais estabelecimentos. 
Em 93,9\% dos processos foram solicitados apenas 1 (hum) medicamento, 0

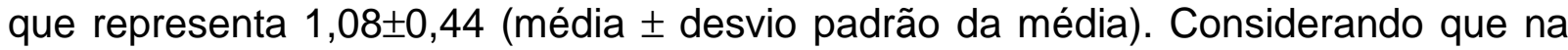
maioria das patologias faz-se necessário a utilização da politerapia é possível supor que os outros medicamentos se encontram contemplados nos protocolos clínicos propostos pelo SUS. Se isto realmente ocorrer, apesar de todos os questionamentos, o SUS vem implementado ações e serviços que parecem atender à população, pelo menos na terapia do Câncer e nas demais doenças identificadas nesta pesquisa.

A pesquisa mostrou que foram solicitados 60 tipos diferentes de medicamentos; dos quais $68,3 \%$ prescritos seguindo a Denominação Comum Brasileira (DCB), de modo a possibilitar a aquisição de qualquer produto farmacêutico que contenha referido princípio ativo, o que favorece a pesquisa de preço em busca da melhor oferta. Todavia, um percentual ainda grande de 31,7\%, trazia na ação a prescrição do medicamento pelo nome de marca, o que impede a intercambialidade, isto é, a substituição da especialidade farmacêutica pelo genérico, cujo preço se apresente menor ou equivalente. Neste contexto, é fácil perceber um comprometimento ainda maior dos recursos financeiros empregados pelo Estado, visto que estes produtos geralmente se apresentam no mercado com o preço mais elevado.

Ao cruzar as informações referentes ao condutor da ação e forma prescrita, observa-se que dos 360 medicamentos demandados, distribuídos em 60 tipos distintos de especialidades farmacêuticas, $30 \%$ foram solicitados pelo nome de marca (Tabela 7). Destaca-se que isto ocorreu mais intensamente, em termos proporcionais, nas ações conduzidas por advogado particular (37\%). No cruzamento das duas variáveis ao invés do total de processos $(n=347)$, considerou-se o total de medicamentos demandados $(n=360)$.

Dessa forma, é possível supor que exista uma espécie de parceria envolvendo múltiplos atores, capaz de estimular a "escolha". Ressalta-se que em decorrência destes medicamentos, na maioria das vezes, não possuírem similares, sendo produzidos por um único laboratório, acaba por criar a possibilidade de a indústria farmacêutica praticar o preço que considerar satisfatório. Ajuizada uma ação, os gestores do SUS são obrigados a comprá-los por meio de importação, sem nenhuma possibilidade de negociação de preços (Chieffi; Barata, 2010). 
Tabela 7 - Frequência da forma de prescrição, segundo o tipo de condutor dos processos judiciais, Ceará, janeiro a dezembro de 2010

\begin{tabular}{|c|c|c|c|c|}
\hline \multirow{2}{*}{$\begin{array}{l}\text { Forma } \\
\text { prescrita }\end{array}$} & \multicolumn{4}{|c|}{ Condutor da ação f (\%) } \\
\hline & Defensoria & MP & Particular & Total \\
\hline DCB & $49(71,0)$ & $152(72,4)$ & $51(63,0)$ & $252(70)$ \\
\hline Marca & $20(29,0)$ & $58(27,6)$ & $30(37,0)$ & $108(30)$ \\
\hline Total & 69 & 210 & 81 & 360 \\
\hline
\end{tabular}

Quanto à característica político administrativa das ações, pode-se observar que todos os medicamentos solicitados apresentavam registro junto à ANVISA (Agência Nacional de Vigilância Sanitária). Isto significa que os medicamentos em questão atendem aos requisitos mínimos de segurança biológica e eficácia terapêutica estabelecidos por esta agência reguladora.

O aumento das demandas judiciais decorre muitas vezes da insuficiência da assistência farmacêutica prestadas pelo SUS e pelos planos de saúde; atuação da indústria farmacêutica e advogados para criar mercado para seus produtos; alianças formadas entre corporações farmacêuticas e grupos de defesa de pacientes; solicitação de medicamentos que estão fora dos protocolos clínico-terapêuticos vigentes no país e/ou não disponíveis no mercado nacional; fatores financeiros e econômicos do SUS, dentre outros. Faz-se necessário repetir que esses fatores, em nosso país, desorganizam as finanças públicas e desviam recursos de ações programadas, no âmbito da atenção coletiva (Sant'ana, 2009), para atender a demanda individualizada. "[...] o fato é que saúde não tem preço, mas tem custo [...]" (Jorge Júnior et al., 2009, p.18).

Por fim, faz-se necessário destacar que neste estudo foram avaliadas 347 demandas judiciais direcionadas à COASF. Trata-se de um número bem reduzido quando se considera a população do Estado. Surge por fim um questionamento: o SUS, apesar de tudo, atende a grande maioria da população, ou o cidadão não encontra condições de concretizar seu direito e se cala, quer por falta de conhecimento, quer pela dificuldade de acionar o poder judiciário? 


\section{Considerações finais}

Muitos medicamentos requeridos nas ações analisadas existem como parte integrante dos protocolos clínico-terapêuticos e, poderiam ser adquiridos através de processos administrativos, sem a necessidade da provocação do Poder Judiciário, que só deveria ser chamado a participar em caso de comprovada omissão. É possível que isto seja resultado do desconhecimento

Se de fato ocorresse uma parceria entre o executivo e o judiciário, quanto às questões que envolvem a assistência farmacêutica, as sentenças prolatadas pareceriam mais justas para ambos os lados, ao priorizar a utilização dos medicamentos padronizados, considerados eficazes e seguros; ao avaliar se o medicamento solicitado já não está contemplado nos esquemas terapêuticos sob outro nome (DCB e/ou marca); se não compreendem os me-toos, medicamentos da mesma classe terapêutica, o que justificaria a utilização do medicamento padronizado.

Apesar de o Estado alegar a impossibilidade fática de cumprimento dos direitos fundamentais demandados nas ações judiciais em face da teoria da reserva do possível, tais preceitos constitucionais de universalidade e integralidade às ações e serviços de saúde vem sendo assegurados nas demandas judiciais. Quanto à igualdade material (equidade), não ficou evidente a sua concretização.

Por fim, as demandas judiciais de medicamentos fundamentam-se no direto à saúde, relacionando-se diretamente à vida e à dignidade. A sua concretização deve ser assegurada por tratar-se de serviço de relevância pública, todavia, as decisões precisam ser embasadas em verdadeiro conhecimento das políticas públicas existentes, de modo que a via judicial seja acionada somente em caso de comprovada ameaça de omissão, e não apenas, nos casos de desconhecimento da parte litigante.

\section{Referências}

ANDRADE, Eli lola Gurge et al. A judicialização da saúde e a política nacional de assistência farmacêutica no Brasil: gestão da clínica e a medicalização da justiça. Rev. Med, 18(4): 46-50, supl. 4, 2008. [data da consulta: 27 out. 2010] Disponível em: $<$ http://rmmg.medicina.ufmg.br/index.php/rmmg/article/viewDownloadInterstitial/102/8 2>.

BIGOLIN, Giovani. A reserva do possível como limite à eficácia e efetividade dos direitos sociais. Buscalegis.ccj.ufsc.br, 2004. [data da consulta: 27 out. 2010] 
Disponível em: $\quad<$ http://www.egov.ufsc.br/portal/sites/default/files/anexos/1565815659-1-PB.pdf>.

BRASIL. Ministério da Saúde. Conselho Nacional dos Secretários de Saúde. Para Entender a Gestão do Programa de Medicamentos de Dispensação em Caráter Excepcional. Coleção Documenta. Brasília: Ministério da Saúde, 2004. v. 3, 247 p. Disponível em: <http://www.conass.org.br/admin/arquivos/documenta3.pdf>. Acesso em: 10 mar. 2010.

CHIEFFI, Ana Luíza; BARATA, Rita Barradas. Judicialização da política pública de assistência farmacêutica e eqüidade. Cad. Saúde Pública, Rio de Janeiro, 25(8): 1839-1849, ago. 2009.

Ações judiciais: estratégia da indústria farmacêutica para introdução de novos medicamentos. São Paulo, Rev. Saúde Pública, 44(3); 421-9, jun., 2010.

HADDAD, Cássio Furtine. Transtuzumabe no câncer de mama. Rev. Femina. São Paulo, 38(2):1-6, fev., 2010. [data da consulta: 05 maio 2011] Disponível em: http://files.bvs.br/upload/S/0100-7254/2010/v38n2/a001.pdf.

JORGE JÚNIOR, Alberto Grosson et al. Constituição Federal após 20 anos: reflexões. Campinas, SP: Millenium, 2009.

MACHADO, Felipe Rangel de Souza. Contribuições ao Debate da Judicialização da Saúde no Brasil. Revista de Direito Sanitário, São Paulo, 9(2):73-91, São Paulo, 2008.

MACHADO, Marina Amaral de Ávila et al. Judicialização do acesso a medicamentos no Estado de Minas Gerais, Brasil. Rev. Saúde Pública, São Paulo, 45(3): 590-598, jun., 2011.

MORAES, Alexandre. Constituição do Brasil interpretada e legislação constitucional. (6. ed.) São Paulo: Atlas, 2006.

MARTINS, Ives Gandra da Silva; MENDES, Gilmar Ferreira; NASCIMENTO, Carlos Valder do. Tratado de Direito Constitucional. (2. ed.) São Paulo: Saraiva, 2010.

NAFFAH FILHO, Michel; CHIEFFI, Ana Luíza; CORREA, Maria Cecília M. M. A. SCodes: um novo sistema de informações sobre ações judiciais da Secretaria de Estado da Saúde de São Paulo. Bepa, 7(84):18-30, dez., 2010.

PESSOA, Nívia Tavares. Perfil das solicitações administrativas e judiciais de medicamentos impetradas contra a Secretaria de Saúde do Estado do Ceará. Fortaleza, UFC, 2007. Dissertação (mestrado em Ciências Farmacêuticas). Ceará, Faculdade de Farmácia, Enfermagem e Odontologia, Universidade Federal do Ceará, 2007. 163p

SANT'ANA, João Maurício Brambati. Essencialidade e Assistência Farmacêutica: Um estudo exploratório das demandas judiciais individuais para 0 acesso a medicamentos no estado do Rio de Janeiro. Dissertação (Mestrado) Rio de janeiro, Fundação Oswaldo cruz. Escola Nacional de Saúde Pública Sergio Arouca, Fundação Oswaldo Cruz, 2009. 93p.

SCAFF, Fernando Facwy. Reserva do possível, mínimo existencial e direitos humanos. Revista Direito e Justiça - Reflexões Sócio-juridicas, 5(8):146-159, jun., 2006. [data da consulta: 07 jul. 2011] Disponível em: <http://www.scaff.adv.br/000001/20091210/000001000000/000000000002.pdf>. 
TAVARES, André Ramos. Curso de direito constitucional. (6. ed.), São Paulo: Saraiva, 2008.

VALE, Thiago Rodrigues do. A Defensoria Pública como pilar do acesso à Justiça, Goiânia, UFG, 2009. Monografia Jurídica (Graduação em direito). Faculdade de Direito, Universidade Federal de Goiás Direito, 2009. 76p

VIEIRA, Fabiola Sulpino; ZUCCHI, Paola. Distorções causadas pelas ações judiciais à política de medicamentos no Brasil. Rev Saúde Pública, Rio de Janeiro, 41(2): 21422, 2007. 